\begin{tabular}{|c|}
\hline Journal of Political Science \\
(A Peer-Reviewed, Open Access International Journal) \\
ISSN 2362-1273 (Print); ISSN 2773-8132 (Online) \\
Volume 21, February 2021, pp. 100-108 \\
https//: www.ejournal of pncampus.edu.np/journals/ips/ \\
\hline
\end{tabular}

\title{
Diaspora and Cultural Identity: A Conceptual Review
}

\author{
Nagendra Bahadur Bhandari, PhD \\ Department of English \\ Prithvi Narayan Campus, Pokhara \\ Corresponding Author: Nagendra Bahadur Chhetri,Email: nagendra@pncampus.edu.np \\ DOI: https://doi.org/10.3126/jps.v21i0.35268
}

Received 10 December, 2020, Reviewed 15 December 2020, Published 1 February 2021

\begin{abstract}
The theorists vary in their conceptualizations of diaspora and cultural identity of immigrants. Broadly speaking, the theorizations of diaspora can be categorized into four different groups with their focus on diverse aspects of immigrants' lives. The first classical phase describes the forced migration of immigrants including victimhood diaspora of Jewish, Africans and Armenians. The second conceptualization incorporates historical, cultural and social diversities of people living in the diaspora. Critiquing the second phase, the third group of theorists deconstructs bipolar notions of the home and host country, and celebrates the inconsistencies, and fluidities of immigrants' identities in diasporic third space. In contrast, the fourth conceptualizations emphasizes on relevance of the origin and historical exploitation of people of poor countries. Both the historical experiences and present negotiations play decisive roles in the formation of cultural identity of immigrants. The present article briefly reviews different conceptualizations of the diaspora and cultural identity of immigrants.
\end{abstract}

Keywords: Being, becoming, cultural identity, diaspora, immigrants

\section{Introduction}

The transborder movements of human beings have been the recurrent phenomena of the history of human civilization. These movements also give birth to the communities of immigrants living away from their homeland which is known as diasporas. The recent developments of the fast means of transportation, information technologies, international trade and labour movements lead to flourishing of diasporic communities. The conceptualizations of diaspora and immigrants' subjectivity substantiate the various causes and phases of international movements. Robin Cohen (2008) chronicles four phases of diaspora examining different theoretical postulations. The initial classical phase includes only victimhood diaspora: the immigrants who have been forcefully sent out of their native 


\section{Diaspora and Cultural Identity: A Conceptual Review}

countries. The second phase extends the victimhood diaspora by incorporating historical, cultural and social diversities of immigrants. The third social constructionist phase focuses on formation of cultural identity of immigrants by deconstructing the bipolar notions of the home and host country. It celebrates the inconsistencies, and fluidities of immigrants' identities in diasporic third space. Conversely, the fourth consolidation phase emphasizes on relevance of the origin and historical exploitation of people of poor countries. Similarly, Stuart Hall (1994), in his postulation of cultural identity, emphasizes the role of both historical experiences and present negotiation in the formation of cultural identity of immigrants. The present article makes a brief survey of different conceptualizations of the diaspora and cultural identity of immigrants.

\section{Different Phases of Diaspora}

Diaspora generally refers to the mass migration of people, and creating settlement and community as a consequence of migration. Initially it denoted to dispersal of Jewish community. Later on, the term includes various transnational migration and community formation. Consequently, the theorists vary in their conceptualization of diaspora. Thomas Faist (2010) succinctly sums up the three characteristics of various definitions of diaspora: the causes of migration or dispersal, cross-border experiences and the incorporation of migrants into the second cultural space (p.12). However, theorists vary in these areas while conceptualizing diaspora and problematic cultural identity of immigrants. Apparently, immigrants' cultural identity emerges out of interaction of their past and present in the third space of diaspora. In this sense Hall (1994) conceptualizes being, shared historical experience and cultural practices and becoming, present interaction jointly contribute in formation of cultural identity of immigrants. However, theorists differ in their postulations of diaspora which affects the conceptualization of the cultural identity of immigrants.

In Cohen's categorization, the first classical phase is more concerned with causes of migration and dispersal. The classical use was mainly confined to the study of the Jewish's forced dispersal and traumatic experience. From the 1960s and 1970s, the classical meaning was systematically extended. It began to include the dispersion of Africans, Armenians and the Irish. These immigrants conceived their dispersal resulting from "cataclysmic event that has traumatized the group as a whole, thereby creating the central historical experience of victimhood at the hands of cruel oppressor" (Cohen, 2008, p. 1). This phase is more concerned with the traumatic causes of dispersion.

The forced dispersal, traumatic historical experiences, collective memory of the home land, lack of integration in the second cultural space, a quest of return, and persistent link with the origin are key components of classical conceptualization of diaspora. However, Cohen (2008) underscores that this paradigm ignores the heterogeneity of diaspora. Diaspora is not a homogenous phenomenon. Temporal, cultural and spatial factors along with class, gender and generation of people influence diasporic experiences.

The modern diaspora results from not only traumatic historical experience but also from people's quest for better prospect in life through jobs and business. Cohen's second phase of conceptualization of diaspora incorporates the social, cultural and historical heterogeneity. Safran (1991) initiated the second phase in the 1980s. Safran argues that diaspora is a metaphoric designation to describe different categories of people: aliens, expatriates, 


\section{Diaspora and Cultural Identity: A Conceptual Review}

immigrants, expellees and political refugees. Because of differing historical experiences and relationships to the first and second space, they are bound to be a more varied cluster of diasporas than the groups designated in phase one. Safran acknowledges such diversity in his conceptualization.

Safran enumerates the collective experience into six points. Safran's common features include dispersal from a specific origin, retention of a collective memory of the home land, marginalization and alienation in the second space, desire to return to their home land, commitment to the prosperity and safety of their homeland, and ethno and communal consciousness and solidarity. With their constant consciousness of the homeland, the immigrants feel of loss, nostalgia and alienation.

Critiquing the second phase theorists, Cohen (2008) explicates the social constructionist theory of diaspora in the third phase. Cohen's postmodernist postulation seeks to "decompose two of the major building blocks previously delimiting and demarcating the diasporic idea, namely 'homeland' and 'ethnic/religious community'" (p. 1). Identities are deterritorialized, constructed and deconstructed. Precisely, concepts of diasporain response to this complexity should necessarily incorporate fluidity and flexibility in identity. Along this postmodernist conjecture of diaspora, James Clifford (1994) opposes Safran's six principles for their failures to accommodate some of the significant precepts of diaspora. Moreover, Clifford differentiates the terms exile, diaspora and immigration. Clifford (1994) consider the Fourth World people diasporas since dispersed people, including tribal ones share common "historical experiences of dispossession, displacement, adaptation ” (p. 309). Rather he recognizes the similarities within the diasporic consciousness.

Brah (1996) in Cartographies of Diaspora: Contesting Identities terms the diasporic consciousness a homing desire. For her home; "is a mythic place of desire in the diasporic imagination. In this sense it is a place of no return, even if it is possible to visit the geographical territory that is seen as the place of 'origin'” (1996, p. 188). So, she discusses the homing desire instead of homeland. Home has become the homing desire and home becomes into an essentially placeless. A historical narrative of journeys, her narrative reposes different forms of relationality internal to and among diasporic formations, and thus, varied, disputed and differentiated in the process of construction of a common 'we'. Unlike many of the diaspora critics, she reaffirms that the immigrants abroad would necessarily not desire to return to the homeland. The members of a diasporic community, in their claim for citizenship in the second space, eventually lose their desire to return to the homeland.

Brah's diaspora space is occupied not only by the immigrants along with their descendants but also by indigenous people. Diasporans share common cultural space with indigenous people in communities in the second space. She cites the diaspora of "England" with the African-Caribbean, the Irish, Asian and Jewish communities to expose a convergence of economic, political, cultural and psychic processes. As a result, diasporans remain in the nexus of various forms of power relationship. The existence of power relations in discourses, institutions, and practices also influence diaspora. She brings "all subordinate classes, genders, ethnicities or sexualities within its orbit” (Brah, 1996, p. 185) to signal inequities of power. Instead of discussing diasporas in terms of majority-minority relations, she propounds a circulatory of a multi-axial understanding of power. One group of migrants in one dimension can be considered a "minority" while they can be taken for the majority from other dimensions. 


\section{Diaspora and Cultural Identity: A Conceptual Review}

The notion of origin and sense of belonging alone cannot acknowledge the inherent heterogeneity of diaspora. There are a lot of differences and divisions within and among diasporic communities. At one point, Floya Anthias (1998) focuses on internal divisions with ethnic communities or to the possibilities of selective cultural negotiations between communities:

The lack of attention given to transethnic solidarities, such as those against racism, of class, of gender, of social movements, is deeply worrying from the perspective of the development of multiculturality, and more inclusive notions of belonging. For a discourse of antiracism and social mobilization of a transethnic (as opposed to a transnational) character, cannot be easily accommodated, with in the discourse of the diaspora, where it retains its dependence on 'homeland' and 'origin', however configured. (p. 577)

In Anthias's concept, diaspora needs to accommodate the transethnic, gender sensitive and anti-racist concerns and issues. Inadequate to describe the kaleidoscopic phenomena of diaspora, the bi-polar concept of the first and second space needs an in-depth examination.

In line with the heterogeneity in the diaspora, Hall (1994) speculates the diasporic experience as "defined, not by essence or purity, but by the recognition of a necessary heterogeneity and diversity; by a conception of 'identity' which lives with and through, not despite, difference; by hybridity" (p. 235). He further states that diasporic identities are those "which are constantly producing and reproducing themselves anew, through transformation and difference" (p. 235). Likewise, Bhabha (1994) moves away from the bipolar model of thefirst and second space to a tripolar one which initiating the in-between space between the first and second space.

As a consequence of such paradigmatic shift in conceptualization of diaspora, the genre has moved away from a tragic mode linked to the experience of diaspora as loss, nostalgia and a longing for the past. It embraces the appealing theme of positive immigration and selfreinvention abroad. Consequently, it has become increasingly divorced from the notion of exile and closer to that of residence in a foreign country. It is an arena for the creative melding of cultures and the formation of new hybrid, mixed identities in the third space.

However, such concept of formation of hybrid identity ignores sufferings of the underprivileged in the diapsora. The experiences of underprivileged vary from the privileged. The underprivileged suffers more than the privileged. They have been victim of economic, political and cultural injustice and exploitation. The social constructionist theorists just examine formation of cultural identity of immigrants ignoring the discrimination and injustice of dominant groups. They fail to explain the full spectrum of immigrant experiences: political, social and economic injustice.

The economic exploitation and political agenda have occupied space in discourse of diaspora in the fourth phase of Cohen's division. Kral (2009) asserts that ideas of hybridity and the third space without political efficacy to the historically marginalized group substantiate the neoliberal political agenda:

In fact, if we are to judge by recent developments in the field of diasporic studies, the locus of the diasporic has failed to become the energetic arena of political demands one might have expected it would become. Theories of in-betweenness like Bhabha's theory of the third space have come in for 


\section{Diaspora and Cultural Identity: A Conceptual Review}

harsh criticism - Bhabha's concept of hybridity in particular has been accused of serving the agenda of neo-liberalism. (p.18)

Kral points out the diaspora studies' deviation from its radical critical stance. It has moved away from paradigms of foregrounding strong confrontational positioning and power struggle.

Cohen expresses that there is resuscitation of strong political agenda by reinscribing the confrontational component in the fourth phase. Incorporating Marxistideas, Kral (2009) alleges post colonial as a depoliticization practice. Helinks postcoloniality to a perennial problem of erosion in the concept of nation by highlights an open field of cosmopolitanism. But by doing so, it has dropped the notion of class and has subsequently become depoliticized. This has had serious consequences at a time when globalization has become more predatory.

Tololyan (2000), in "Elites and Institution in the Armenia Diaspora History", takes a middle path between social constructionist and radical stance. In a radical stance, an attachment to the place remains central to the diasporic identity. Contrary to this position, social constructionists explicate a process of forming an identity through social interactions. Subscribing both of the views, Tololyan (2000) argues that identity is a part of social negotiation but the home country remains decisive in the interaction (p.125). The phase of consolidation is characterized by a revised reaffirmation of the diasporic idea, including its core elements, common features and ideal types.

Cohen (2008) adopts the same middle path, arguing that both hybrid and transcultural third space and the relevance of origin are equally important in diasporic studies. He extends Safran's (1991) six features to nine, concerning the evolution and characters of diasporic group in the second space. Cohen affirms with Safran (1991)in dispersal from homeland, idealization and collective memory of the home country, desire to return and sense of solidarity among ethnic people. However, he differs in acknowledging trouble relationship in the second space as well as creative possibility of diaspora.

In recapitulation, the concept of diaspora has undergone a process of transformation from simply a dispersion of people to the formation of identity in the third space. It initiates with traumatic experiences of forced immigrants and gradually incorporates various forms of voluntary and involuntary transborder movements and settlements. In extending the conceptualization, the theorists of diaspora include cultural, historical and political heterogeneities of immigrants in their postulations. The next group of theorists focuses on the formation of fluid cultural identity of immigrants by deconstructing the binary of home and host country. Critiquing them, there is another theorization of diaspora which emphasizes the relevance of origin of immigrants. In such theoretical debates, the cultural identity of immigrants remains a pertinent issue. The following section discusses various conceptualizations of cultural identity.

\section{Cultural Identity}

Cultural identity of an individual involves in dynamic processes of interaction with multiple factors. Social interaction and personal awareness play decisive role in the formation of human identity. More importantly, the social interactions of an individual have been equally 


\section{Diaspora and Cultural Identity: A Conceptual Review}

informed by his/her past and present living. Incorporating these factors, the conceptualizations of an immigrant's cultural identity can broadly be categorized into three groups.The first conceptualization, which is known as essentialism, emphasizes on the essential characters of a cultural community which an individual inherits as a member of the community. The second conceptualization asserts that cultural identity of an individual evolves out of social interaction in course of living. This social constructivist approach denies possessing any essential characters which are immutable. The third approach which is postulated by Stuart Hall merges both the essentialist and social constructivism approaches in his proposition of cultural identity. He equally emphasizes the role of cultural genealogy and social interaction in the formation of an individual's cultural identity. The following section briefly discusses these theorizations of cultural identity.

The essentialist approach of cultural identity argues that every community possesses certain essential and core values "that determine its uniqueness and specificity" (Petkova, 2005, p. 17). The essential values which they terms as "a social or cultural spirit of community" function as a "higher existential essence" of the community (p. 17). They are considered as eternal aspects of reality and they are independent of human beings beyond time and place. Living in the community, an individual internalizes these essential values. Apparently, the identification with the community is "considered to be a natural psychological phenomenon inherent in every individuals” (p.17). In this sense, inheriting essential communal values and norms, an individual acquires a cultural identity that transcendent time and space. This approach, however, undermines the role of personal experience and social interaction in forming cultural identity of an individual.

Critiquing the essentialist's emphasis on essential values, social constructivism underlines on social interaction of an individual for the formation of cultural identity. This approach rejects "the existence of essential or innate features" (p. 17) of a cultural community that transcendent time and space. Rather, it claims that cultural identity of an individual is a social construct. This approach claims that cultural communities and cultural identities are "continuously constructed, shaped and reshaped by individuals" (p.19). Moreover, nations and sometimes even ethnicities are presented as the result of conscious and deliberate social engineering (Kedourie, 1960, p. 1). So, the theorists like Anderson (1983) and Hobsbawn (1983) coin terminologies like "imagined communities" (Anderson, 1983, p. 6) and "Invented Tradition" (Hobsbawn, 1983, p. 1) to refer to national and cultural communities. In such social interactions, an individual may take up different cultural identities in different social and cultural context and their cultural identity undergoes in a constant process of formation and reformation.

There is nothing essential and permanent in social constructivism's approach of cultural identity. In contrast, an individual involves in a constant process of negotiation with multiple social and cultural allegiances. Anthias (1998) succinctly elaborates that an individual's cultural identity comprises a number of aspects, for instances ethnicity, religion, language, nationality, gender, sexuality and social class. These aspects intersect, that is, the different aspects interrelate and crisscross within an individual's life and in social interactions. As a result, cultural identity is considered as unstable and plural in this perspective. However, this approach ignores the shared cultural values and common historical experience of a community which provide a constant reference for defining cultural identity of an individual. 


\section{Diaspora and Cultural Identity: A Conceptual Review}

Incorporating essentialist and social constructivist approaches, Hall (1994) postulates a third approach of cultural identity. He succinctly conceptualizes the cultural identity of immigrants in his postulation of being and becoming. In his concept of being, he emphasizes the similarities among a group of people on the basis of their shared cultural values and historical experience. In contrast, he emphasizes similarities and differences among an imagined cultural group in his idea of becoming. Both, being and becoming jointly influence in the formation of cultural identity.

Hall's (1994) postulation of being emphasizes the similarities, the oneness and the underlying essence of people. There is an authentic cultural identity, a true self, which people with a shared history and ancestry share in common. He explains:

Within the terms of this definition, our cultural identities reflect the common historical experiences and shared cultural codes which provide us, as 'one people', with stable, unchanging and continuous frames of reference and meaning, beneath the shifting divisions and vicissitudes of our actual history. (p. 223)

The oneness is understood as fixed reference and meaning which reflects the general shared cultural codes and common historical experiences. This definition emphasizes that the authentic cultural identity, which is hidden underneath the more superficial or artificially imposed selves, enacts as a creative force.

Hall (1994) claims that such essentialist conceptualization of identity possesses powerful and creative force. It encourages exploration of the hidden histories and provides motivation and an organizational logic for many right based social movements: feminism, anti-racism, anti-colonialism. Moreover, Hall argues that the quest of rediscovery is an act of imaginary reunification. Such acts impose "an imaginary coherence on the experience of dispersal and fragmentation, which is the history of all enforced diasporas" (p. 224). A work of art and literature can represent the imaginary coherence. So, the imaginary coherence is matter of quest and representation.

Cultural identity is a matter of representation for Hall. The practice of representation is associated with the positions of subject who represents it. Hall's discourse of representation invokes his personal experience as a Jamaican-born youth in the British diaspora. The position of subject undergoes transformations in historical and geographic spaces, ultimately changing the paradigms of cultural identity. The implication of the positionality or standpoint of the subject deconstructs the fixed and stable identity. Hall (1994) argues that all discourse including the discourse of identity is "placed" (p. 223). As a result, identity keeps on changing. It is an ongoing process of production that is constituted within representation. We cannot speak for long about "one experience, one identity with much exactness without coming to acknowledge "the ruptures and discontinuities" (p. 225). Although the common historical essence and oneness are essential factors of identity, they fail to encompass the dynamic nature of identity. Incorporating the dynamism of identity, Hall proposes his second conceptualization of identity.

Hall's (1994) second definition of "cultural identity" emphasizes the similarities and the differences amongst an imagined cultural group. He elaborates:

Cultural identity, in this second sense, is a matter of 'becoming' as well as of 'being'. It belongs to the future as much as to the past. It is not something 


\section{Diaspora and Cultural Identity: A Conceptual Review}

which already exists, transcending place, time, history and culture. Cultural identities come from somewhere, have histories. But, like everything which is historical, they undergo constant transformation. Far from being eternally fixed in some essentialised past, they are subject to the continuous 'play' of history, culture and power. (p. 225)

Hall explicates that identity is contingent and not ahistorical or immutable. Identity is an ongoing process of 'becoming' as well as of 'being'. It equally belongs to both the future and the past. Depending on the pre-given and pre-determined aspects only partially define identity. It transcends time and place. Although it is historical, it changes in and through power relations that are spatial and cultural.

The past does not just wait idly. It exists in relationship with present in various ways such as material condition, social and cultural practices and meaning. It is an active force. It transforms, and can be liberating or debilitating. This is why Hall is so apt in describing identity as "the names we give to the different ways we are positioned by, and position ourselves within, the narratives of the past" (p. 225). The narrative of the past is an unavoidable and active force in shaping identity. The past is in constant negotiation with present. The negotiation of past and present shapes our cultural identity. Such a negotiation renders third space in the diaspora in which the fluid and multiple cultural identities of immigrants evolve.

\section{Conclusion}

The concept of diaspora has undergone a process of transformation from simply a dispersion of people to the formation of identity in the third space. In the first phase, it primarily accounts for traumatic experience of forced dispersal of a certain group of people. These immigrants have lost their homeland and have got refuge in the host country. The forced migration influences their diasporic experience. In the second extended phase, the conceptualization of diaspora proliferates including diverse groups of the immigrants and their experiences. The cultural, social and political heterogeneities along with historical trauma and longing to home country are given priority in this phase. The third phase of the conceptualization of diaspora emphasizes on the formation of subjectivity of the immigrants. Borrowing concept of Postmodernism, the theorists of this phase insist on fluidity, instability and transitariness of human identity. They deconstruct the traditional bipolar concept of the home and host country and consider the diaspora as a hybrid cultural intersection which they term as the third space. They are also known as social constructionist group. However, the theorists of the fourth phase, disagrees with social constructionists, for depoliticizing the diaspora studies. They partially accept the social constructionist's ideas while insisting on the notion of origin to address the historical exploitation and injustice. In these theorizations, the cultural identity of immigrants remains a crucial issue. The immigrants living in constant processes of negotiation of the cultural practices of their home and host land. They are not free from their cultural origin from where they along with their ancestors have come from. Their shared historical experience and common cultural codes of their homeland influence their sense of being. At the same time, their present negations and interactions with foreign cultural practices and people of the host land constantly influence their subjectivities. As a result of such bicultural 


\section{Diaspora and Cultural Identity: A Conceptual Review}

affiliations, their cultural identity embodies multiplicities and fluidities negotiating in the third space of the diaspora.

\section{References}

Anderson, B. (1983). Imagined communities: Reflection on the origin and spread of nationalism. Verso

Anthias, F. (1998). Evaluating 'diaspora': Beyond ethnicity? Sociology, 32 (3),557580. www.jstor.org/stable/42855957.

Bhabha, H. K. (1994).The Location of culture. Routledge.

Brah, A. (1996). Cartographies of diaspora: Contesting identities. Routledge.

Clifford, J. (1994). Diasporas. Cultural Anthropology, 9 (3), 302-338. www.jstor.org/ stable/656365.

Cohen, R. (2008).Global diaspora: An introduction. Routledge.

Faist, T. (2010). Diaspora and transnationalism: What kind of dance partners? In R. Baubock, \& T. Faist (Eds.), Diaspora and transnationalism: Concepts, theories and methods (pp.9-34). Amsterdam University.

Hall, S. (1994). Cultural identity and diaspora. In P. Williams \& L. Chrisman (Eds.), Colonial discourse and post colonial theory: A reader. 222-237. Columbia UP.

Hobsbdwm, E. (1983). Introduction: inventing traditions. In E. Hobsbawm \& T. Ranger (Eds.), The Invention of tradition. 1-14. Cambridge.

Kedurie, E. (1960). Nationalism. Blackwell.

Kral, F. (2009). Critical identities in contemporary anglophone diasporicliterature. Palgrave Macmilan.

Petkova, D. \& Lehtonen, J. (Eds.). (2005). Cultural identity in intercultural context. University of Jyvaskyla

Safran, W. (1991). Diasporas in modern societies myths of homelands and return. DiasporaI, 1(1), 83-99. https://doi:10.1353/dsp.1991.0004.

Toloyal, K. (2000). Elites and institution in the Armenia diaspora history. Diaspora: A Journal of Transnational Studies, 9 (1),107-136. www.transcomm.ox.ac.uk/working\%20papers/WPTC-01-21\%20Tololyan.doc.pdf. 